To the Editors:

\title{
Measles, mumps, rubella (MMR) vaccine - a reply (1)
}

\author{
Ceylon Medical Journal 2011; 56: 185
}

I am writing with reference to the Letter to the Editor, on the MMR vaccine, which appeared in the September 2011 issue of The Ceylon Medical Journal [1]. There are certain aspects of that letter written by a learned professor which need closer scrutiny.

The author contends that there are a considerable number of cases of deafness due to mumps which occurred during the last ten years. Deafness caused by mumps is listed in the literature as a rare complication, and writer of the letter himself admits that it occurs in approximately 5 out of 100,000 cases of mumps [2]. If, as he says, there are 6 to 9 cases of deafness due to mumps seen in each ENT unit in the country each year, and calculating for a conservative estimate of 10 ENT units in the country, we should have had numbers ranging from 120,000 to 180,000 cases of mumps in the country each year. Such numbers would have been in epidemic proportions. Everybody except perhaps the author is aware that such large numbers of cases of mumps were never seen over the last ten years. I believe that the personal communication that was quoted regarding the numbers of cases of deafness caused by mumps is not tenable and does not stand up to rational analysis. It is totally at variance with our clinical experience.

I do agree that the MMR vaccine is a very desirable addition to the National Expanded Programme of Immunisation. However, I must express some concerns regarding the timing of the vaccine at one year. Before 1980s, when the measles vaccine was introduced, there were large numbers of cases of measles with major complications which occurred in our country. Considerable numbers of these occurred in the second six months of infancy. The measles vaccine was given at nine months of age as maternal immunity was due to immunity following natural infection and the antibodies in the mother that had crossed over to the baby afforded protection only up to about six months. Thereafter, the immunity wanes, and was thought to be at a very low level at nine months of age. The vaccine given at that time was not likely to be interfered with by the crossed antibodies. At the present time, maternal immunity is not due to natural infection but due to measles vaccine, as most mothers today were born after its introduction. There has been uncertainty as to whether the immunity produced by the vaccine in the mother wanes off quicker than that produced by natural infection. In fact, a recent study from Belgium has shown that vaccinated women had significantly lower IgG antibodies against measles, and their infants had significantly lower antibody concentrations compared to infants of mothers with naturally acquired immunity [3]. In that study, at six months of age, more than 99 per cent of babies of vaccinated women and 95 per cent of babies of naturally immune women had lost the protection from their mother's antibodies. At age between nine and twelve months no babies had any levels of protection. There are recommendations to consider giving the MMR vaccine earlier to cover the immunity gap [4]. By not giving the measles vaccine at nine months and giving the MMR at one year, one may be leaving a group of infants in the second six months of infancy quite vulnerable to measles.

Finally, the last few lines of the quoted Letter to the Editor, and particularly its tone leave a lot to be desired. I personally find that the sentiments expressed in those few lines are totally unjustified, abrasive, objectionable and unacceptable. I was not present at the Vaccine Summit in the year 2000 but I am sure that the people who opposed the introduction of MMR in the year 2000 had very good reasons for their course of action. Some of these were probably financial concerns. For a developing country like Sri Lanka such considerations are important. It is unfair to hold those people to be personally responsible for the occurrence of even a single case of deafness following mumps. In the same context, currently there is a great debate on the feasibility of introducing the human papilloma virus vaccine to the Expanded Programme of Immunisation in the country. Those who are not in favour of it probably have very good reasons for the stand that they have taken. By analogy, ten years hence, there is the totally unjustifiable risk of them being held responsible for cases of carcinoma of the cervix that occur in the country.

\section{References}

1. Lamabadusuriya SP. Measles, mumps, rubella (MMR) vaccine. Ceylon Medical Journal 2011; 56: 135.

2. Rare complications of mumps. Available from http:// www.nhs.uk/Conditions/Mumps/Pages/Complications.aspx Accessed 08-10-2011.

3. Leuridan E, Hens N, Hutse V, Ieven M, Aerts M, Van Damme P. Early waning of maternal measles antibodies in era of measles elimination: longitudinal study. British Medical Journal 2010; 340: 1626.

4. Alleyne R. Babies should be given MMR jab earlier to cover immunity 'gap' for measles. Available from http://www. telegraph.co.uk/health/healthnews/7736958/ Accessed 08-10-2011.

\section{B J C Perera}

Consultant Paediatrician. 